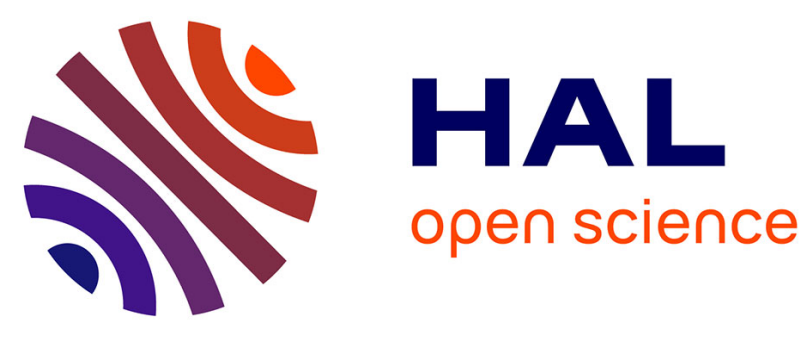

\title{
The highly conserved synapsin domain E mediates synapsin dimerization and phospholipid vesicle clustering
}

Ilaria Monaldi, Massimo Vassalli, Angela Bachi, Silvia Giovedi, Enrico Millo, Flavia Valtorta, Roberto Raiteri, Fabio Benfenati, Anna Fassio

\section{To cite this version:}

Ilaria Monaldi, Massimo Vassalli, Angela Bachi, Silvia Giovedi, Enrico Millo, et al.. The highly conserved synapsin domain E mediates synapsin dimerization and phospholipid vesicle clustering. Biochemical Journal, 2010, 426 (1), pp.55-64. 10.1042/BJ20090762 . hal-00479196

\section{HAL Id: hal-00479196 https://hal.science/hal-00479196}

Submitted on 30 Apr 2010

HAL is a multi-disciplinary open access archive for the deposit and dissemination of scientific research documents, whether they are published or not. The documents may come from teaching and research institutions in France or abroad, or from public or private research centers.
L'archive ouverte pluridisciplinaire HAL, est destinée au dépôt et à la diffusion de documents scientifiques de niveau recherche, publiés ou non, émanant des établissements d'enseignement et de recherche français ou étrangers, des laboratoires publics ou privés. 


\title{
THE HIGHLY CONSERVED SYNAPSIN DOMAIN E MEDIATES SYNAPSIN DIMERIZATION AND PHOSPHOLIPID VESICLE CLUSTERING
}

Ilaria Monaldi ${ }^{1,2}$, Massimo Vassalli $^{3}$, Angela Bachi ${ }^{4}$, Silvia Giovedi ${ }^{1,7}$, Enrico Millo ${ }^{1}$, Flavia Valtorta $^{4,5,7}$, Roberto Raiteri ${ }^{6}$, Fabio Benfenati ${ }^{1,2,7}$ and Anna Fassio ${ }^{1,7}$

\begin{abstract}
${ }^{1}$ Department of Experimental Medicine, University of Genoa, Viale Benedetto XV 3, 16132, Genoa, Italy; ${ }^{2}$ Department of Neuroscience and Brain Technologies, The Italian Institute of Technology, Via Morego 30, 16163 Genoa, Italy; ${ }^{3} \mathrm{CNR}$ Institute of Biophysics, Genoa, Italy; ${ }^{4}$ S. Raffaele Scientific Institute, Milan, Italy; ${ }^{5}$ San Raffaele Vita-Salute University, The Italian Institute of Technology Unit of Molecular Neuroscience, Milan, Italy; ${ }^{6}$ Department of Biophysical Engineering and Electronics, University of Genoa, Italy; ${ }^{7}$ Istituto Nazionale di Neuroscienze, Italy.
\end{abstract}

Short title: Synapsin dimerization and vesicle clustering by synapsin domain E

Key Words: Synapsin, Synaptic vesicles, Exocytosis, Liposomes, AFM, FRET

\section{Correspondence should be sent to:}

Fabio Benfenati, MD

Department of Experimental Medicine

University of Genova

Viale Benedetto XV, 3

16132 Genova - Italy

tel. $\quad+390103538183$

fax. $\quad+390103538194$

e-mail: fabio.benfenati@unige.it 


\section{SYNOPSIS}

Synapsins are abundant synaptic vesicle (SV)-associated phosphoproteins that regulate synapse formation and function. The highly conserved $\mathrm{COOH}$-terminal domain $\mathrm{E}$ was shown to contribute to several synapsin functions, ranging from formation of the SV reserve pool to regulation of the kinetics of exocytosis and SV cycling, although the molecular mechanisms underlying these effects are unknown. We used a synthetic 25-mer peptide encompassing the most conserved region of domain $\mathrm{E}$ (Pep-E) to analyze the role of domain $\mathrm{E}$ in regulating the interactions between synapsin I and liposomes mimicking the phospholipid composition of SVs (SV-liposomes) and other presynaptic protein partners. In affinity chromatography and cross-linking assays, Pep-E bound to endogenous and purified exogenous synapsin I and strongly inhibited synapsin dimerization, indicating a role in synapsin oligomerization. Consistently, Pep-E (but not its scrambled version) counteracted the ability of holosynapsin I to bind and coat phospholipid membranes, as analyzed by AFM topographical scanning, and significantly decreased the clustering of SV-liposomes induced by holosynapsin I in Förster Resonance Energy Transfer assays, suggesting a causal relationship between synapsin oligomerization and vesicle clustering. Either Pep-E or a peptide derived from domain $\mathrm{C}$ was necessary and sufficient to inhibit both dimerization and vesicle clustering, indicating the participation of both domains in these activities of synapsin I. The data provide a molecular explanation for the effects of domain $\mathrm{E}$ in nerve terminal physiology and suggest that its effects on the size and integrity of SV pools are contributed by the regulation of synapsin dimerization and SV clustering. 


\section{INTRODUCTION}

Small synaptic vesicles (SVs) are the central organelle at the synapse. SVs contain quanta of neurotransmitter (NT) to be released into the synaptic cleft, undergo cycles of exo-endocytosis and are distributed into at least two functionally distinguishable pools within the axon terminals, namely the readily releasable pool (RRP) made of SVs actively involved in exocytosis and the reserve pool (RP) which represents a reserve of NT to sustain transmission during periods of intense activity (1). Several proteins participate in the regulation of SV cycling at the synapse and the clarification of the molecular mechanisms underlying SV trafficking are fundamental for the understanding of synaptic function and plasticity.

The proteome of SVs is known in great detail and consists of several copies of a surprising diversity of trafficking proteins, some of which are entirely SV-specific (2). A family of SV-associated phosphoproteins playing a key role in the maintenance of SV pools and in the regulation of NT release are the synapsins (Syns; 3,4). Syns bind reversibly to the cytoplasmic surface of SVs through interactions with both SV protein and lipid components (5-8) and are believed to tether SVs to each other and to actin filaments (9-11). Syns are encoded by three distinct genes (SYN1, SYN2 and SYN3) in mammals and alternative splicing of these genes gives rise to multiple different isoforms. Syns are major substrates for several kinases including CaMK I/II/IV, PKA, Erk, Cdk5 and Src (12,13). Phosphorylation differently affects the ability of Syns to bind SV and actin $(11,14-$ 18 ) and serves as an important functional switch to regulate SV trafficking.

In addition to phosphorylation, oligomerization appears to be fundamental in mediating Syn functions. Syns have been reported to form homo- and hetero- dimers and tetramers via a dimerization surface which is not overlapping with the phospholipid binding domains and is modulated by ATP binding $(8,19-21)$ and dimerization appears to be required for correct targeting of some Syn isoforms to the axon terminal (22). Moreover, Syns have been proposed to maintain SV integrity and uniform size by coating the cytoplasmic surface of SVs by virtue of their high surface activity $(23,24)$. Direct visualization of the Syn coat on planar lipid bilayers and demonstration of stabilizing activity of Syn on SV membranes were reported using atomic force microscopy (AFM) and phosphorus nuclear magnetic resonance (10,25-27).

Syns are composed of individual and common domains (Fig. 1). The $\mathrm{NH}_{2}$-terminal portion of all Syns is highly conserved and consists of domains A-C, whereas the COOH-terminal portion is more variable and consists of a variable combination of domains D to J. Among the latter domains, domain $\mathrm{E}$ is the most conserved and is shared by all a-type Syn isoforms $(3,4)$. Domain $\mathrm{E}$ has been reported to play important roles in Syn function. Injection of a specific antibody against domain $\mathrm{E}$ in the lamprey reticulo-spinal synapses (28) as well as injection of a synthetic 25-mer peptide encompassing the most conserved region of domain E (Pep-E) in the squid giant synapse $(29,30)$ or overexpression of the same peptide in cerebellar Purkinje cells (31) dramatically decreased the number of SV in the RP, leaving the size of the RRP substantially unaffected. Moreover, Syn Pep-E seems to participate also in postdocking functions by slowing down the kinetics of NT release and making synapses more susceptible to depression (29). In hippocampal neurons, domain E, in tandem with domain $\mathrm{C}$, is a positive determinant for the correct synaptic targeting of synapsin Ia (22) and biochemical studies revealed that Pep-E selectively competes for the binding of Syn I to Factin (30).

To understand the molecular mechanisms underlying these effects, we analyzed the role of domain $\mathrm{E}$ in the interactions between Syn I and liposomes mimicking the phospholipid composition of SVs (SV-liposomes), as well as between Syn I and other presynaptic protein partners by using affinity 
chromatography, cross-linking, Förster Resonance Energy Transfer (FRET) and AFM using synthetic Pep-E. The data demonstrate that domain E participates in the formation of Syn I dimers and that inhibition of domain E-mediated oligomerization disrupts the ability of Syn to coat and aggregate SV-liposomes. 


\section{EXPERIMENTAL}

Materials. Antibodies to VAMP 2, SNAP-25, Rab 3A, syntaxin and synaptotagmin were obtained from Synaptic Systems GmbH (Goettingen, Germany). Antibodies against Syn I (10-22), and Syn II (19-21) were raised in our laboratory. Antibody against Syn III (RU-486) was a kind gift from H.T. Kao (Brown University, Providence, RI). Bovine brain phosphatidylcholine (PC), bovine brain phosphatidylserine (PS), bovine brain phosphatidylethanolamine (PE), bovine liver phosphatidylinositol (PI), N-[4-nitrobenzo-2-oxa-1,3-diazole]-L-a-phosphatidylethanolamine (NBD-PE) and N-(lissamine rhodamine B sulfonyl)-L- $\alpha$ - phosphatidylethanolamine (LRh-PE) were obtained from Avanti Polar Lipids (Alabaster, AL), stored at $-20^{\circ} \mathrm{C}$ in the dark and used within 3 months. Streptavidin-Sepharose beads were from GE Healthcare Life Sciences (Milano, Italy). All other chemicals were from Sigma (Milano, Italy).

Peptide synthesis. The peptide SLSQDEVKAETIRSLRKSFASLFSD (rat SynIa ${ }^{680-704}$; Pep-E), its scrambled version STESLKVEDSLSAKFRAISRFLQSD (ScrPep-E), the rat peptide corresponding to the squid C5 peptide (30) AYMRTSVSGNWKTNTGSAMLEQI (rat SynI ${ }^{325-347}$; Pep-C; ) and its scrambled version STWTEAINLSGMYTMKGVNQRAS (ScrPep-C) were manually synthesized using the standard method of solid phase peptide synthesis which follows the 9fluorenylmethoxycarbonyl (Fmoc) strategy with minor modifications (32). To obtain biotinylated peptides (BiotPep-E and BiotScrPep-E, respectively), either Pep-E or SrcPep-E was labelled by direct coupling of biotin on the solid support to the $\mathrm{NH}_{2}$-terminal of the protected peptide sequences during the synthesis. Synthesized compounds were purified by reverse phase high performance liquid chromatography (RP-HPLC) on a Shimadzu LC-9A preparative HPLC equipped with a Phenomenex C18 Luna column $(21.20 \times 250 \mathrm{~mm})$. Peptide quality and purity were confirmed by HPLC-MS/MS analysis (data not shown).

Preparation of extracts of purified rat brain synaptosomes. Subcellular fractionation of the rat cerebral cortex was performed as previously described (33). Highly purified synaptosomes were obtained by centrifugation of the resuspended crude synaptosomal pellets ( $\mathrm{P} 2$ fraction) at 32,500 $\mathrm{x}$ $\mathrm{g}$ for $5 \mathrm{~min}$ on a discontinuous four-step 3-23\% Percoll gradient and by collecting the third and fourth interfaces, as previously described (34). The synaptosomal fraction was then resuspended in Binding Buffer (150 mM NaCl, $50 \mathrm{mM}$ Tris, $\mathrm{pH}$ 7.4, 0.1\% SDS, 1\% Nonidet P-40, 0.5\% sodium deoxycholate, $200 \mathrm{mM}$ PMSF, $2 \mu \mathrm{g} / \mathrm{ml}$ pepstatin, $1 \mu \mathrm{g} / \mathrm{ml}$ leupeptin) for $1 \mathrm{~h}$ on ice and extracted by centrifugation at $400,000 \times \mathrm{g}$ for $1 \mathrm{~h}$ in a Beckman TL-100 ultracentrifuge. The soluble fraction was then immediately subjected to affinity chromatography (see below).

Affinity chromatography with biotinylated peptide E. Either BiotPep-E or BiotScrPep-E $(250 \mu \mathrm{g})$ was immobilized with $400 \mu \mathrm{l}$ of settled, pre-equilibrated Streptavidin-Sepharose beads. After an overnight adsorption at $4{ }^{\circ} \mathrm{C}$ under gentle rotation in small columns, the samples were incubated with freshly prepared synaptosomal extracts (2-3 $\mathrm{mg}$ protein). After an overnight incubation at 4 ${ }^{\circ} \mathrm{C}$, columns were packed and extensively washed with Binding Buffer followed by a final wash with detergent-free Binding Buffer. Elution of the bound proteins was performed with $5 \mathrm{mM}$ biotin in detergent-free Binding Buffer. Samples were then separated by SDS/PAGE and analyzed by silver staining followed by MS MALDI-ToF or by immunoblotting. 
MALDI-ToF analysis. The excised bands were reduced, alkylated and digested overnight as previously described (35). Proteins were identified by MALDI-ToF peptide mass mapping. One $\mu 1$ of the supernatant of the digestion was loaded onto the MALDI target using the dried droplet technique and $\alpha$-cyano-4-hydroxycinnamic acid as matrix. MALDI-MS measurements were performed on a Voyager-DE STR time of flight (ToF) mass spectrometer (Applied Biosystems, Foster City, CA). Spectra were accumulated over a mass range of 750-400 Daltons (Da) with a mean resolution of about 15,000 . Spectra were internally calibrated using trypsin autolysis products and processed via Data Explorer software version 4.0.0.0 (Applied Biosystems). Alkylation of cysteine by carbamidomethylation, and oxidation of methionine were considered as fixed and variable modifications respectively. Two missed cleavages per peptide were allowed, and a mass tolerance of $50 \mathrm{ppm}$ was used. Peptides with masses correspondent to those of trypsin and matrix were excluded from the peak list. Proteins were identified by searching against MSDB protein database (MSDB 20050701 restricted to MAMMALIA (292819 SEQUENCES) using MASCOT algorithm (36). Probability-based protein identification by searching sequence databases using mass spectrometry data. Electrophoresis 20: 3551-67).

Synapsin I cross-linking assays. The formation of Syn I dimers was assessed by cross-linking experiments using the catalytic oxidation of sulfhydryl groups by the o-phenantroline/copper complex (37). Briefly, $1 \mu \mathrm{g}$ of purified Syn I solubilized in $200 \mathrm{mM} \mathrm{NaCl}, 20 \mathrm{mM} \mathrm{NaPO}$, pH 7.4 was incubated with $0.5 \mathrm{mM} \mathrm{CuSO}_{4}$ and $1 \mathrm{mM}$ o-phenanthroline for $40 \mathrm{~min}$ at room temperature in the presence or absence of Pep-E or ScrPep-E, Pep-C or ScrPep-C in various combinations. At the end of the incubation period, the reaction was stopped by the addition of $50 \mathrm{mM}$ EDTA followed by $\beta$-mercaptoethanol-free SDS sample buffer. The cross-linked complexes were separated by SDSPAGE on $6 \%$ polyacrylamide gels under non-reducing conditions, transferred to nitrocellulose membranes and detected by immunoblotting with an anti-synapsin I antibody.

SV-liposomes aggregation assays. Phospholipid vesicles mimicking the phospholipid composition of SV (PC:PE:PS:PI:cholesterol = 40:32:12:5:10) were made by sonication as described previously (10). SV-liposome were resuspended in buffer A (150 mM NaCl, $3 \mathrm{mM} \mathrm{NaN3}, 10 \mathrm{mM}$ Hepes-OH, pH 7.4). Fluorescently labeled SV-liposomes had the same lipid composition with the addition of the appropriate amounts ( $2 \%$ of the total lipid, w/w) of NBD-PE or LRh-PE either alone (single labeled liposomes) or in combination (double labeled liposomes). Changes in Syn-induced vesicle aggregation in the presence of either Pep-E or ScrPep-E were followed by analyzing FRET between the energy donor NBD-PE and the acceptor LRh-PE, as previously described (10). Synapsin I (100 $\mathrm{nM}$ )-induced aggregation in the presence or absence of various concentrations of Pep-E or ScrPepE was followed by monitoring FRET at $22{ }^{\circ} \mathrm{C}$ using a PerkinElmer Life Sciences LS-50 spectrofluorometer equipped with a thermostated sample holder. In the first assay (aggregation/fusion assay) the fluorescence donor and acceptor were incorporated into separate vesicle populations then the two populations of vesicles $(100 \mu \mathrm{g}$ of phospholipid for each population) were mixed, and FRET was measured by exciting the donor at $470 \mathrm{~nm}$ and following either the decrease in NBD emission at $520 \mathrm{~nm}$ (NBD quencing) or the increase in LRh emission at $590 \mathrm{~nm}$ (excitation and emission slits of 2.5 and $5 \mathrm{~nm}$, respectively). In the second assay (fusion assay), one population of vesicles containing the same amount of both fluorophores (50 $\mu \mathrm{g}$ of phospholipid, $2 \%$ labeled phospholipids) was mixed with unlabeled vesicles (150 $\mu \mathrm{g}$ of phospholipid). Membrane fusion, leading to intermixing of labeled and unlabeled membrane components, results in a decrease in the surface density of donor and acceptor fluorophores and thereby in a decrease in FRET between NBD and LRh. Under these conditions, pure aggregation of vesicles not accompained by fusion is silent per se, but can be evaluated by an enhancement in the 
rate and extent of vesicle fusion induced by addition of $\mathrm{Ca}^{2+}(3 \mathrm{mM})$. Alternatively, aggregation of unlabeled liposomes was evaluated by a light scattering/turbidity assay as previously described (10). Samples containing $20 \mu \mathrm{g}$ of phospholipids were incubated in $150 \mu \mathrm{l}$ buffer $\mathrm{A}$ in the absence or presence of Syn I (200 nM) and/or the various peptides. Turbidity was measured by reading the absorbance at $325 \mathrm{~nm}$ as a function of time at $22{ }^{\circ} \mathrm{C}$ in a DU-8 spectrophotometer (Beckman Coulter, Milano, Italy) equipped with a thermostated sample holder.

AFM imaging. All Atomic Force Microscopy (AFM) measurements were taken using an Agilent 5400 system, (Agilent Technologies) equipped with a $90 \mu \mathrm{m}$ x $90 \mu \mathrm{m}$ scanner and a low coherence laser to avoid interference of the laser beam during force-distance curves. Images were acquired in contact mode (512 x 512 pixels) using triangular silicon nitride cantilevers (MLCT, Microlever type, Veeco) with a nominal spring constant of $0.06 \mathrm{~N} / \mathrm{m}$. AFM samples were prepared by using a mica substrate. The solution containing the phospholipids or the synapsin/peptide were gently added directly into the AFM liquid cell without removing the mica substrate by using a syringe and small Teflon tubes, while keeping the same imaged area during addition. For lipid bilayer preparation, $200 \mu \mathrm{l}$ of a $10 \mathrm{mg} / \mathrm{ml}$ solution of phospholipid vesicles (prepared as for the vesicles aggregation assay in the absence of labeled compounds) in saline buffer were deposited onto freshly cleaved mica. After an overnight incubation at room temperature (under water saturated atmosphere to prevent evaporation of the solution), the cell was rinsed with buffer solution to eliminate excess phospholipids. The presence of a uniform bilayer on the mica surface was assessed by AFM imaging and indentation. As previously reported (25), the AFM image of lipid bilayers showed a flat uniform surface which could be pierced by the AFM tip in the course of force-distance curves, resulting in a highly reproducible and characteristic jump of few nanometers (corresponding to the thickness of the double layer) at a force of around 10-20 nN. Each sample was checked for the presence of the double lipid layer before proceeding with the addition of Syn and/or peptides.

Other procedures. Synapsin I was purified from bovine brain as described (9). Protein concentration assay, SDS-PAGE electrophoretic transfer of proteins to nitrocellulose membranes (Schleicher and Schuell, Milano, Italy) and immunoblotting were carried out according to standard procedures using the ECL chemiluminescence as a detection system. 


\section{RESULTS}

\section{Peptide E binds to synapsins}

To understand the molecular mechanisms by which domain $\mathrm{E}$ exerts its activity, affinity chromatography experiments from nerve terminal extracts were performed to reveal putative interacting synaptic proteins using a peptide (Pep-E) encompassing the most conserved region of domain E. Detergent extracts of Percoll-purified rat forebrain synaptosomes were loaded onto BiotPep-E columns and bound proteins were eluted with biotin and analysed by SDS-PAGE. Silver staining showed that several proteins specifically bound to biotin Pep-E columns, but not to the control columns in which ScrPep-E was immobilized (Fig 2A). MALDI-ToF MS revealed that SynIa was bound to Pep-E columns (indicated by arrow \#1 in Fig. 2A and corresponding to gi|6686305|sp|P09951|SYN1_RAT[6686305] synapsin I; matched peptides 8 out of 18 measured peptides, sequence coverage $18 \%$, score 73 ). Other proteins were detected in the eluates by mass spectrometry, including tubulin $\beta$ 2B chain and ATP synthase $\alpha$ chain (Fig. 2A). However, except for Syn Ia, the other bound proteins were neither synaptic nor enriched in brain tissue and their relevance remains elusive. To confirm the interaction between Pep-E and SynI and to investigate on other possible interactions of domain $\mathrm{E}$ with synaptic proteins which might have escaped detection by silver staining, we performed immunoblot analysis on affinity chromatography samples using antibodies against specific Syn isoforms, SNARE proteins and Rab3A. Both Syn Ia/Ib and Syn $\mathrm{IIa} / \mathrm{IIb}$ bound to the Pep-E, but not to the control column, in contrast with synIII or the other tested presynaptic proteins which did not bind to immobilized Pep-E (Fig. 2B).

\section{Peptide E inhibits synapsin dimerization}

Synapsin I is known to form homodimers or heterodimers with SynII that are believed to play a role in SV clustering and trafficking $(10,20,38)$. Domain $E$ has been reported to interfere with the ability of SynI to bind and bundle actin filaments (30) and bundling is believed to be contributed by selfassociation of Syn molecules (9). Therefore we analyzed the role of domain E in Syn dimerization using the copper-phenantroline method to covalently link synapsin dimers (39) in the presence of Pep-E or ScrPep-E. Synapsin monomers and dimers were separated by non-reducing SDS-PAGE and visualized by immunoblotting (Fig. 3A, upper panel). Upon exposure to the crosslinking agent, a significant fraction of SynI formed dimers of 160-170 kDa molecular mass. Interestingly, Pep-E significantly inhibited Syn dimer formation in a concentration-dependent manner with an $\mathrm{IC}_{50}$ of $180 \pm 9 \mu \mathrm{M}$, whereas the same concentrations of ScrPep-E were virtually ineffective (Fig. 3A, lower panel). As structural studies performed on recombinant synapsin $\mathrm{C}$ domain or $\mathrm{ABC}$ domains demonstrated that the formation of Syn dimers and tetramers is mediated by stretches of domain $\mathrm{C}(19,21)$, we investigated whether peptides belonging to the $\mathrm{C}$ and $\mathrm{E}$ domains (Pep-C and Pep-E, respectively) have a synergistic action in inhibiting synapsin dimerization. Similar to Pep-E, Pep-C dose-dependently inhibited the formation of synapsin dimers, with a higher potency $\left(\mathrm{IC}_{50}\right.$ of $61 \pm 5 \mu \mathrm{M}$ ), while its scrambled version was ineffective. However, when Pep-C was tested in the presence of a Pep-E concentration corresponding to the $\mathrm{IC}_{50}$, the association of the two peptides did not further increase the inhibition of Syn dimerization with respect to the effect of either peptide (Fig. 3B).

\section{Peptide $\mathbf{E}$ inhibits the formation of synapsin islands on phospholipid bilayers}


We used AFM to directly observe the effect of the domain E peptide on the oligomerization of Syn I bound to membranes mimicking the phospholipid composition of native SVs. Consistent with previous observations (25), a time-dependent formation of protein clusters on top of the phospholipid surface was observed after the injection of Syn I. A representative AFM image taken 5 min after the in situ addition of $10 \mu \mathrm{M}$ Syn I (Fig. 4A,C) shows the formation of extended $(1 \div 2$ $\mu \mathrm{m}$ ) "islands" of about $\sim 2.1 \mathrm{~nm}$ in height (Fig. 4D,E). Force-distance curves performed on top of the Syn I "islands" did not show the characteristic jump into contact, suggesting that Syn I makes the underlying lipid bilayer more stable than the bare bilayer, and prevents the tip from penetrating the phospholipid membrane. The effect of Pep-E on the Syn I aggregation properties was tested by adding increasing concentrations of either the peptide or its scrambled version immediately before the addition of Syn I. A typical AFM image obtained 5 min after the in situ addition of $10 \mu \mathrm{M}$ Syn on a bilayer sample pretreated with $250 \mu \mathrm{M}$ peptide $\mathrm{E}$ is presented in Fig. $4 \mathbf{B}$. The islands formed in the presence of Pep-E were markedly smaller and with different shapes, while their height $(2.1 \pm$ 0.4 and $1.9 \pm 0.4 \mathrm{~nm}$ for Syn I and Syn I+Pep-E, respectively) was not affected (Fig. 4F,G). When the concentration of Syn I was increased to $25 \mu \mathrm{M}$, a very large and confluent protein plateau was formed, that appeared almost homogeneous over a $3 \mu \mathrm{m}$ x $3 \mu \mathrm{m}$ scale (Fig. 5A). However, when Pep-E was added immediately before Syn I (Fig. 5B), it significantly altered the ability of Syn I to form confluent "islands", whereas ScrPep-E had only a small effect (Fig. 5C). When a standard flooding algorithm was used to quantify the percentage of "rised" regions, the area of Syn bilayer coverage obtained at $25 \mu \mathrm{M}$ Syn I was strongly decreased in the presence of Pep-E $(250 \mu \mathrm{M})$, while was affected to a lesser extent by the scrambled version of the peptide (Fig. 5D).

\section{Peptide E inhibits the synapsin-induced aggregation of phospholipid vesicles}

Synapsin I was shown to cluster phospholipid vesicles mimicking the composition of SV (10). Thus, we investigated whether Pep-E was able to interfere with the Syn-induced SV-liposome clustering by using fluorometric assays sensitive to either vesicle aggregation (followed or not by fusion) or fusion only (see Experimental). Both assays confirmed that Syn I induces vesicle clustering without triggering fusion, as the addition of Syn I readily increased FRET in the aggregation assay (Fig. 6), whereas it potentiated the fusogenic effect of $\mathrm{Ca}^{2+}$ in the fusion assay (Fig. 7). Pep-E and ScrPep-E were devoid of any effect on vesicle aggregation and fusion by themselves (Figs. 6B, 7B). Interestingly, Pep-E virtually abolished the effect of Syn I on vesicle aggregation, while its scrambled version was ineffective (Fig. 6A,B). Consistent results were obtained in the fusion assay, in which Pep-E, but not its scrambled version, blocked the potentiating effect of Syn I on the fusogenic effect of $\mathrm{Ca}^{2+}$ in a concentration-dependent manner (Fig. 7A,B). We also studied whether Pep-C and Pep-E have a synergistic action when tested in the inhibition of phospholipid vesicle clustering evaluated by a turbidity/light scattering assay (10). As observed in the dimerization experiments, either peptide inhibited the Syn I-induced vesicle clustering $\left(\mathrm{IC}_{50} \cong\right.$ 40 and $62 \mu \mathrm{M}$ for Pep-C and Pep-E, respectively). Moreover, when increasing concentrations of Pep-C were incubated in the presence of a fixed concentration of Pep-E $(200 \mu \mathrm{M})$, the two peptides had an occlusive effect, suggesting that both $\mathrm{C}$ and $\mathrm{E}$ domains participate in vesicle clustering (Fig. 8). 


\section{DISCUSSION}

Synapsin domain E has been implicated in mediating key Syn functions such as maintenance of the reserve pool and regulation of the kinetics of exocytosis in distinct experimental systems. Injection of anti-domain E antibodies into the lamprey reticolo-spinal axons disrupted the RP of SVs upon activity (28). On the other hand, injection of Pep-E into the terminal of the squid giant axon or overexpression of Pep-E in cerebellar Purkinje cells of L7-transgenic mice dramatically decreased the RP of SVs and perturbed the kinetics of exocytosis (29,31). However, the molecular mechanisms by which domain $\mathrm{E}$ exerts its function remain largely unresolved.

Previous data suggested that the physiological effects of Syn domain E are generated through a perturbation of the interactions of Syn I with F-actin. Actin is known to be a fundamental player linking regulation of SV cycling and trafficking between functional SV pools to synaptic efficacy (40). It has been demonstrated that Pep-E, as well as a highly conserved peptide from domain C characterized by similar physiological effects, competitively inhibit the Syn-actin interactions (30). Thus, their physiological effects could be ascribed to an inhibition of SV tethering to the actin cytoskeleton which is believed to regulate size and maintenance of the RP (11,41-43). However, the physiological role of actin in the regulation of SV pool size and trafficking was recently questioned (44). Actin filaments were shown to be less abundant inside the SV clusters than near the plasma membrane at the endocytic periactive zone and around the SV clusters (45-48). Moreover, at the giant lamprey synapse disruption of actin cytoskeleton led to depletion of the RP of SV upon activity, by impairing the transport of SV from the endocytic periactive zone to the SV cluster and decreasing the cluster size upon stimulation (46), while at hippocampal synapses it had no significant effects on the SV pool size (47). The characteristic distribution of F-actin at presynaptic sites, around rather than within the SV cluster, suggests a scaffolding function of the actin meshwork, rather than a direct role in clustering (44). Interestingly, Syns have been reported to disperse from the SV cluster to the endocytic zone during synaptic activity $(45,49)$. Taken together, these data suggest that Syn-actin interactions may be more important for the regulation of SV trafficking between distinct pools than for the maintenance of the RP and for SV clustering. Accordingly, the Syn domain E-actin interaction may not be the sole mechanism by which domain E exerts its functions.

In this paper, we addressed the possibility that domain E contributes to SV clustering through additional interactions within the nerve terminal. Our data indicate that the Syn domain E: (i) binds to Syn I and Syn II; (ii) mediates Syn dimerization and participates in the stabilizing effect of Syn on the phospholipid bilayer (iii) is involved in Syn-mediated SV clustering.

Synapsin oligomerization has been demonstrated in living cells expressing distinct Syn isoforms where Syn I/II and Syn II/III heterodimers, in addition to homodimers, were detected (20). The interaction of domain E with Syn I and Syn II, but not Syn III, detected by affinity chromatography in the present paper is in full agreement with the yeast two-hybrid screens which found Syn I and Syn II in the large majority of the specifically isolated prey clones using a domain E-bearing Syn IIa bait (20). The fact that Syn III was excluded from the interaction with peptide E is in line with the low expression levels of this isoform in mature nerve tissue (50) and with previous data demonstrating that Syn III is not able to heterodimerize with Syn I when overexpressed in COS7 cells (20). The involvement of domain $\mathrm{E}$ in the formation of Syn dimers also implicates this domain in the specific targeting of Syns to synaptic terminals. Domain E was identified as a positive determinant of nerve terminal targeting and dimerization was reported to be crucial for bringing to synaptic terminals Syn isoforms with weak targeting potential, such as Syn Ib (22). 
The peptide competition experiments indicate that domain E-mediated Syn dimerization plays a key role in the ability of Syn to coat phospholipid bilayers and to maintain their uniform size and structural integrity $(10,25)$. As Syn I represents $4 \%$ of SV protein, it is thought to cover large portions of the SV surface $(23,25)$ and by this means to have a role in maintaining the uniform shape of SV as well as in preventing random fusion events. The antagonizing effect of Pep-E on the Syn-mediated stabilizing effect of the phospholipid bilayer and on the ability of Syn to dimerize and cluster SV suggests that the maintenance of SV integrity and the prevention of random fusion events are causally linked to Syn oligomerization on the SV membrane.

Synapsin dimerization is thought to play a key role in SV clustering and stabilization as the result of the binding of Syn homo- or heterodimers to adjacent SV. The crystal structure of Syn domain C suggests the presence of a dimerization surface (19) which does not overlap with the membrane binding domains (24), and is therefore a good candidate for mediating SV clustering. Several observations indicate that peptides encompassing critical regions of domain $\mathrm{C}$ and domain $\mathrm{E}$ (Pep-C and Pep-E) alter synaptic function and SV clustering in a similar fashion, suggesting that these two domains directly or indirectly mediate the same interactions of Syns. In fact, both $\mathrm{C}$ and E peptides, injected into the preterminal region of the squid giant axon disassemble SV clusters, slow down the kinetics of release and enhance synaptic depression in response to high frequency stimulation $(29,30)$. Indeed, our data support a concomitant involvement of domain $\mathrm{E}$ and domain $\mathrm{C}$ in the dimerization and vesicle clustering processes. The occlusive effects displayed by the combination of the two peptides, and the observation that each peptide per se is able to disrupt synapsin dimers and vesicle clusters indicate that, under native conditions, stretches belonging to both domain $\mathrm{C}$ and domain $\mathrm{E}$ are involved in the oligomerization of holo-synapsin I and that both interaction sites are required to stabilize the Syn dimer and form the Syn lattice on phospholipid membranes. It is tempting to speculate that either peptide may lead to destabilization of the synapsin conformation involved in the formation of oligomers. Analysis of holosynapsin crystals formed in the presence of the peptides would be required to prove this hypothesis. It is also possible that, although the maximal effect reached in the presence of a single peptide does not exceed the effect obtained in the presence of both $\mathrm{C}$ and $\mathrm{E}$ peptides, the presence of both $\mathrm{C}$ and $\mathrm{E}$ domains may allow a more rapid kinetics of dimerization and clustering in vivo.

In conclusion, although unidentified protein partners and/or regulation of Syn-actin interactions may potentially contribute to its physiological effects, the Syn domain E appears to be directly involved, together with domain C, in the formation of Syn oligomers and in the ability of Syns to form and maintain the SV clusters of the RP. Thus, it is tempting to speculate that the dramatic depletion of the distal SV pool observed in lamprey reticulo-spinal synapses after injection of antidomain E antibody (28), in squid giant synapse after injection of Pep-E (29) or in Purkinje cell terminals overexpressing pep E (31) can be ascribed to a major impairment of Syn oligomerization caused by interference with the interactions mediated by the endogenous domain $\mathrm{E}$. 


\section{ACKNOWLEDGEMENTS}

We thank Drs. Paul Greengard (The Rockefeller University, New York, NY), Hung-Teh Kao (Brown University, Providence, RI) for the gift of anti-synapsin III antibodies and invaluable discussions. Michele Zoli (University of Modena and Reggio Emilia, Modena, Italy) for statistical analysis and helpful discussions. Fabia Filipello, Franco Onofri and Annalisa Furlan (University of Genova and Italian Institute of Technology, Genova, Italy) for precious technical help.

\section{FUNDING}

The project was supported by grants from the Ministry of the University and Research (PRIN 2006 grants to A.F. and F.B.) and Compagnia di San Paolo (to F.B, F.V. and A.F.). The support of Telethon-Italy (GCP05134 and GCP09134), Cariplo Foundation and Fondazione Pierfranco and Luisa Mariani grants (to F.B. and F.V.) is also acknowledged. 


\section{REFERENCES}

1. Rizzoli SO, Betz WJ. (2005) Synaptic vesicle pools. Nat. Rev. Neurosci. 6, 57-69

2. Takamori S, Holt M, Stenius K, Lemke EA, Grønborg M, Riedel D, Urlaub H, Schenck S, Brügger B, Ringler P, Müller SA, Rammner B, Gräter F, Hub JS, De Groot BL, Mieskes G, Moriyama Y, Klingauf J, Grubmüller H, Heuser J, Wieland F, Jahn R. (2006) Molecular anatomy of a trafficking organelle. Cell 127, 831-846

3. Fdez E, Hilfiker S. (2006) Vesicle pools and synapsins: new insights into old enigmas. Brain Cell Biol. 35: 107-115.

4. Baldelli P, Fassio A, Corradi A, Valtorta F, Benfenati F. (2006) The synapsins and the control of neuroexocytosis. In: Regazzi R, editor. Molecular Mechanisms of Exocytosis. Georgetown, TX: Landes Bioscence. pp 62-74.

5. Benfenati F, Greengard P, Brunner J, Bähler M.(1989) Electrostatic and hydrophobic interactions of synapsin I and synapsin I fragments with phospholipid bilayers. J. Cell Biol. 108, $1851-1862$

6. Benfenati F, Bähler M, Jahn R, Greengard P.(1989) Interactions of synapsin I with small synaptic vesicles: distinct sites in synapsin I bind to vesicle phospholipids and vesicle proteins. J. Cell Biol. 108, 1863-1872

7. Benfenati F, Valtorta F, Rubenstein JL, Gorelick FS, Greengard P, Czernik AJ (1992) Synaptic vesicle-associated $\mathrm{Ca} 2+/$ calmodulin-dependent protein kinase II is a binding protein for synapsin I. Nature 359, 417-420

8. Cheetham, J.J., Hilfiker, S., Benfenati, F., Weber, T., Greengard, P., and Czernik, AJ. (2001) Identification of synapsin I peptides that insert into lipid membranes. Biochem. J. 354, 57-66

9. Bähler M, Greengard P (1987) Synapsin I bundles F-actin in a phosphorylation-dependent manner. Nature 326, 704-707

10. Benfenati F, Valtorta F, Rossi MC, Onofri F, Sihra T, Greengard P (1993) Interactions of synapsin I with phospholipids: possible role in synaptic vesicle clustering and in the maintenance of bilayer structures. J. Cell Biol. 123, 1845-1855

11. Ceccaldi PE, Grohovaz F, Benfenati F, Chieregatti E, Greengard P, Valtorta F (1995) Dephosphorylated synapsin I anchors synaptic vesicles to actin cytoskeleton: an analysis by videomicroscopy. J. Cell Biol. 128, 905-912

12. Jovanovic JN, Sihra TS, Nairn AC, Hemmings HC Jr, Greengard P, Czernik AJ (2001) Opposing changes in phosphorylation of specific sites in synapsin I during Ca2+-dependent glutamate release in isolated nerve terminals. J. Neurosci. 21, 7944-7953

13. Onofri F, Messa M, Matafora V, Bonanno G, Corradi A, Bachi A, Valtorta F, Benfenati F (2007) Synapsin phosphorylation by SRC tyrosine kinase enhances SRC activity in synaptic vesicles. J. Biol. Chem. 282, 15754-15767 
14. Jovanovic, J.N., Benfenati, F., Siow, Y.L., Sihra, T.S., Sanghera, J.S., Pelech, S.L., Greengard, P. and Czernik, A.J. (1996) Neurotrophins stimulate phosphorylation of synapsin I by MAP kinase and regulate synapsin I-actin interaction. Proc. Natl. Acad. Sci. U.S.A. 93, 3679-3683

15. Hosaka, M., Hammer, R.E. and Südhof, T.C. (1999) A phosphoswitch controls the dynamic association of synapsins with synaptic vesicles. Neuron $24,377-387$

16. Chi P, Greengard P, Ryan TA. 2001. Synapsin dispersion and reclustering during synaptic activity. Nat. Neurosci. 4, 1187-1193.

17. Chi P, Greengard P, Ryan TA. 2003. Synaptic vesicle mobilization is regulated by distinct synapsin I phosphorylation pathways at different frequencies. Neuron 38, 69-78.

18. Menegon, A., Bonanomi, D., Albertinazzi, C., Lotti, F., Ferrari, G., Kao, H.T., Benfenati F., Baldelli, P. and Valtorta, F. (2006) Protein kinase A-mediated synapsin I phosphorylation is a central modulator of Ca2+-dependent synaptic activity. J. Neurosci. 6(45), 11670-11681

19. Esser L, Wang CR, Hosaka M, Smagula CS, Südhof TC, Deisenhofer J (1998) Synapsin I is structurally similar to ATP-utilizing enzymes. EMBO J. 17, 977-984

20. Hosaka, M. and Südhof, T.C. (1999) Homo- and heterodimerization of synapsins. J. Biol. Chem., 274, 16747-16753

21. Brautigam, C.A., Chelliah, Y. and Deisenhofer, J. (2004) Tetramerization and ATP binding by a protein comprising the A, B, and C domains of rat synapsin I. J. Biol. Chem. 279(12), 1194811956

22. Gitler D, Xu Y, Kao HT, Lin D, Lim S, Feng J, Greengard P, Augustine G.J. (2004) Molecular determinants of synapsin targeting to presynaptic terminals. J. Neurosci. 24, 3711-3720

23. Ho, M., Bähler, M., Czernik, A.J., Schiebler, W., Kezdy, F.J., Kaiser, E.T. and Greengard P. P. (1991) Synapsin I is a higly surface-active molecule. J. Biol. Chem. 266, 5600-5607

24. Cheetham, J.J, Murray, J., Ruhkalova, M., Cuccia, L., McAloney, R., Ingold, K.U. and Johnston, L.J. (2003) Interaction of synapsin I with membranes. Biochem. Biophys. Res. Commun. 309(4), 823-829

25. Pera, I., Stark, R., Kappl, M., Butt, H.J. and Benfenati, F. (2004) Using the atomic force microscope to study the interaction between two solid supported lipid bilayers and the influence of synapsin I. Biophys. J. 87, 2446-2455

26. Murray, J., Cuccia, L., Ianoul, A., Cheetham, J.J. and Johnston, L.J. (2004) Imaging the selective binding of synapsin to anionic membrane domains. Chembiochem. 5, 1489-1494

27. Awizio, A.K., Onofri, F., Benfenati, F. and Bonaccurso, E. (2007) Influence of synapsin I on synaptic vesicles: an analysis by force-volume mode of the atomic force microscope and dynamic light scattering. Biophys. J. 93(3), 1051-1060 
28. Pieribone, V.A., Shupliakov, O., Brodin, L., Hilfiker-Rothenfluh, S., Czernik, A.J. and Greengard, P. (1995) Distinct pools of synaptic vesicles in neurotransmitter release. Nature 375, 493-497

29. Hilfiker, S., Schweizer, F. E., Kao, H. T., Czernik, A. J., Greengard, P. and Augustine, G. J. (1998) Two sites of action for synapsin domain $\mathrm{E}$ in regulating neurotransmitter release. Nat. Neurosci. 1, 29-35

30. Hilfiker, S., Benfenati, F., Doussau, F., Nairn, A.C., Czernik, A.J., Augustine, G.J. and Greengard P. (2005) Structural domains involved in the regulation of transmitter release by synapsins. J. Neurosci. 25, 2658-2669

31. Fassio, A., Merlo, D., Mapelli, J., Menegon, A., Corradi, A., Mete, M., Zappettini, S., Bonanno, G., Valtorta, F., D'Angelo, E. and Benfenati, F. (2006) The synapsin domain E accelerates the exoendocytotic cycle of synaptic vesicles in cerebellar Purkinje cells. J. Cell Sci. $119(20), 4257-4268$

32. Wellings, D.A. and Atherton, E. (1997) Standard Fmoc protocols. Methods Enzymol. 289, 4467

33. Huttner, W.B., Schiebler, W., Greengard, P. and De Camilli P. (1983) Synapsin I (Protein I), a nerve terminal-specific phosphoprotein. III. Its association with sinaptic vesicles studied in a highly purified synaptic vesicle preparation. J. Cell. Biol. 96, 1374-1388

34. Dunkley PR, Jarvie PE, Robinson PJ (2008) A rapid Percoll gradient procedure for preparation of synaptosomes. Nat. Protoc. 3, 1718-1728

35. Shevchenko, A., Wilm, M., Vorm, O. and Mann, M. (1996). Mass spectrometric sequencing of proteins silver-stained polyacrylamide gels. Anal. Chem. $68,850-858$

36. Perkins DN, Pappin DJ, Creasy DM, Cottrell JS. (1999) Probability-based protein identification by searching sequence databases using mass spectrometry data. Electrophoresis 20, 3551-67.

37. Kobashi K (1968) Catalytic oxidation of sulfhydryl groups by o-phenanthroline copper complex. Biochim. Biophys. Acta 158, 239-245

38. Font, B. And Aubert-Foucher, E. (1989) Detection by chemical cross-linking of bovine brain synapsin I self-association. Biochem. J. 264, 893-899

39. Benfenati, F., Ferrari, R., Onofri, F., Arcuri, C., Giambanco, I. and Donato, R. (2004) S100A1 codistributes with synapsin I in discrete brain areas and inhibits the F-actin-bundling activity of synapsin I. J. Neurochem. 89(5), 1260-1270

40. Cingolani, L.A. and Goda, Y. (2008) Actin in action: the interplay between the actin cytoskeleton and synaptic efficacy. Nat. Rev. Neurosci. 9(5), 344-356.

41. Doussau F and Augustine GJ. (2000) The actin cytoskeleton and neurotransmitter release: an overview. Biochimie. 82(4):353-63. Review.

42. Benfenati F, Valtorta F, Chieregatti E, Greengard P (1992) Interaction of free and synaptic vesicle-bound synapsin I with F-actin. Neuron 8, 377-386 
43. Greengard, P., Valtorta, F., Czernik, A. J. and Benfenati, F. (1993) Synaptic vesicle phosphoproteins and regulation of synaptic function. Science 259, 780-785

44. Evergren E, Benfenati F, Shupliakov O.(2007) The synapsin cycle: a view from the synaptic endocytic zone. J Neurosci. Res. 85, 2648-2656

45. Bloom, O., Evergren, E., Tomilin, N., Kjaerulff, O., Low, P., Brodin, L., Pieribone, V.A., Greengard, P. and Shupliakov, O. (2003) Colocalization of synapsin and actin during synaptic vesicle recycling. J. Cell. Biol. 161(4), 737-747

46. Shupliakov, O., Bloom, O., Gustafsson, J.S., Kjaerulff, O., Low, P., Tomilin, N., Pieribone, V.A., Greengard, P. and Brodin, L. (2002) Impaired recycling of synaptic vesicles after acute perturbation of the presynaptic actin cytoskeleton. Proc. Natl. Acad. Sci. U. S. A. 99(22), 1447614481

47. Sankaranarayanan, S., Atluri P.P. and Ryan, T.A. (2003) Actin has a molecular scaffolding, not propulsive, role in presinaptic function. Nat. Neurosci. 6, 127-134

48. Bourne, J., Morgan, J.R. and Pieribone, V.A. (2006) Actin polymerization regulates clathrin coat maturation during early stages of synaptic vesicle recycling at lamprey synapses. J. Comp. Neurol. 497(4), 600-609

49. Tao-Cheng, J.H. (2006) Activity-related redistribution of presynaptic proteins at the active zone. Neuroscience 141(3), 1217-1224

50. Ferreira A, Kao HT, Feng J, Rapoport M, Greengard P. 2000 Synapsin III: developmental expression, subcellular localization, and role in axon formation. J. Neurosci. 20, 3736-3744 


\section{LEGENDS TO THE FIGURES}

Fig.1. Schematic representation of the domain structure of the mammalian synapsin family. Synapsin isoforms are composed of shared $\mathrm{NH}_{2}$-terminal domains (A to $\mathrm{C}$ ) and a mosaic of individual $\mathrm{COOH}$-terminal domains (D-J). The highest degree of conservation is observed for domains $\mathrm{A}, \mathrm{C}$ and $\mathrm{E}$, the latter of which is shared by all the "a" isoforms. Known phosphorylation sites (P) are shown. Only one isoform is represented for Syn III, although multiple isoforms have been described in the adult brain. The functional interactions and kinase specificity of the phosphorylation sites are summarized in the lower panel for the various Syn regions.

Fig. 2. Peptide E interacts with Synapsins I and II. (A) Silver staining of proteins purified from extracts of rat cerebrocortical synaptosomes through either BiotPep-E conjugated columns $(+)$ or BiotSrcPep-E conjugated control columns (-). Specific bands subsequently subjected to MALDIToF analysis and identified are indicated by arrows: synapsin (1), tubulin $\beta$ 2B chain (2) and ATP synthase $\alpha$ chain (3). (B) Affinity chromatography eluates obtained in A were subjected to immunoblotting using various antibodies against synaptic proteins. Synapsin I (Syn I) and Synapsin II (Syn II) were both specifically purified by the BiotPep-E column, whereas the other presynaptic proteins tested, including Syn III, synaptotagmin (Stg), syntaxin (Stx), Rab3A, Snap25 and synaptobrevin/VAMP (Vamp) were undetectable in the eluates. No detectable immunoreactivity was present in the eluates from the BiotSrcPep-E conjugated control columns.

Fig. 3. Either peptide $E(A)$ or peptide $C(B)$ is sufficient to inhibit the formation of synapsin dimers. (A) Purified Synapsin I $(1 \mu \mathrm{g})$ was incubated in $200 \mathrm{mM} \mathrm{NaCl}, 20 \mathrm{mM} \mathrm{NaPO}$, $\mathrm{pH} 7.4$ without (-) or with $0.5 \mathrm{mM} \mathrm{CuSO}_{4} / 1 \mathrm{mM}$ o-phenantroline (XL) for $40 \mathrm{~min}$ at room temperature in the absence (-) or presence of increasing concentrations (in $\mu \mathrm{M}$ ) of either Pep-E or ScrPep-E. The cross-linked Syn complexes were separated by SDS-PAGE under non-reducing conditions, followed by immunoblotting with an anti-Syn I antibodies (upper panel). When Syn I was incubated alone, a major synapsin oligomeric species (dimer at about $170 \mathrm{kDa}$ molecular mass) was generated. When Pep-E (at concentrations $>125 \mu \mathrm{M}$ ) was incubated with Syn I, the Syn dimer completely disappeared, while equal concentrations of ScrPep-E were virtually ineffective. The extent of Syn I dimerization in the presence of either Pep-E (closed symbols) or ScrPep-E (open symbols) was quantified by densitometric analysis of the fluorograms (lower panel). Percentages of dimerization were calculated as the amount of dimer versus the total amount of Syn I in the lane and data are expressed in percent of the value measured in the absence of peptides (Syn I alone) as means \pm sem of at least five independent experiments. Repeated measures ANOVA: $p<0.05$ Pep-E $v s$ ScrPep-E. (B) Purified Syn I $(10 \mu \mathrm{M})$ was incubated under the same conditions described in (A) in the absence $(-)$ or presence of increasing concentrations (in $\mu \mathrm{M}$ ) of either Pep-C, its scrambled version (SrcPep-C) or Pep-C with $200 \mu \mathrm{M}$ Pep-E (upper panel). The extent of Syn I dimerization, quantified as in (A) is shown in the lower panel for Pep-C (closed circles), ScrPep-C (open circles) and Pep-C $+200 \mu \mathrm{M}$ PepE (closed triangles) as means \pm sem of at least five independent experiments. Repeated measures ANOVA: $\mathrm{p}<0.05$ Pep-C vs ScrPep-C, $\mathrm{p}>0.05$ Pep-C vs Pep$\mathrm{C}+$ Pep-E. Curves were fitted according to a three-parameter logistic function using the program Sigmaplot 10.0 (Systat Software, Inc.). 
Fig. 4. Peptide $\mathbf{E}$ alters the synapsin I coverage of phospholipid bilayers. (A) AFM topography image $(20 \mu \mathrm{m} \times 20 \mu \mathrm{m})$ taken 5 min after injection of $10 \mu \mathrm{M}$ Syn I. Circular structures ("islands") on top of the lipid bilayer are clearly visible. The bar indicates the region selected for the profile of panel B. The dashed square identifies the region zoomed in panel C. (B) AFM topography image $(20 \mu \mathrm{m} \times 20 \mu \mathrm{m})$ taken 5 min after injection of $10 \mu \mathrm{M}$ Syn I on a sample previously incubated with $250 \mu \mathrm{M}$ Pep-E. The islands formed in this case are smaller and less regular than in panel A. (C) Three-dimensional representation of a $7 \mu \mathrm{m} \times 7 \mu \mathrm{m}$ region from panel A. (D,F) Height profile (solid line) of two adjacent "islands". The dashed line is a fit of the data with a step profile. The height (d) of the islands calculated from the fit is the same for Syn I alone $(d=2.3 \pm 0.2 \mathrm{~nm}$, panel D) and Syn $\mathrm{I}+$ Pep-E $(\mathrm{d}=2.2 \pm 0.3 \mathrm{~nm}$, panel F). (E, G) Histogram of the height distribution of the pixels. The left peak, centered on $0 \mathrm{~nm}$ height, represents the bilayer level. The right peak corresponds to the Syn island level. The solid line is a fit of the distribution with a double Gaussian profile. The mean value of the height difference between the lipid bilayer and the synapsin "islands" was $2.1 \pm 0.3 \mathrm{~nm}$ for Syn I (E) and $2.2 \pm 0.4 \mathrm{~nm}$ for Syn I + Pep-E (G), despite the area covered by Syn I (related to the height of the higher peak in the histogram) was remarkably larger in absence of Pep-E.

Fig. 5. Peptide $\mathbf{E}$ inhibits the formation of synapsin islands on phospholipid bilayers. (A-C) AFM topography images $(20 \mu \mathrm{m} \times 20 \mu \mathrm{m})$ of a lipid bilayer after the addition of $25 \mu \mathrm{M}$ Syn I in the absence (A) or presence of either $250 \mu \mathrm{M}$ Pep-E (B) or $250 \mu \mathrm{M}$ ScrPep-E (C). The images were filtered to be processed with a standard flooding algorithm in order to determine the percentages of "rised" regions (relative coverage, RC). The histogram in panel D reports the mean $\mathrm{RC}$ value $\pm \mathrm{sd}$ calculated on a data set of 5 independent replications. One-way ANOVA, F $(2,12)=187.803 \mathrm{p}<$ 0.001. Post-hoc Bonferroni's multiple comparison test: $* * *, \mathrm{p}<0.001$ vs control; ${ }^{\circ}{ }^{\circ}, \mathrm{p}<0.001$, vs ScrPep-E.

Fig. 6. Peptide $\mathbf{E}$ inhibits the synapsin-induced aggregation of phospholipid vesicles. (A) Representative traces from an aggregation experiment. Syn I (100 nM) either alone or in the presence of $30 \mu \mathrm{M}$ Pep-E or ScrPep-E was added at time 0 to equimolar amounts of NBD- and LRh-labeled vesicles (100 $\mu \mathrm{g}$ of phospholipids, $2 \%$ labeled). Fluorometric analysis was performed and the increase in the acceptor fluorescence was followed as a function of time. (B) For each experimental condition, the extent of aggregation was calculated by subtracting the fluorescence value recorded before the treatments from the steady state fluorescence value recorded 6 min after Syn and/or peptide addition. Data are means \pm s.e.m. of 4 experiments run in triplicate. One-way ANOVA, $\mathrm{F}(5,18)=11.54, \mathrm{p}<0.001$. Post-hoc Bonferroni's multiple comparison test: *, $\mathrm{p}<0.05$, $* * * \mathrm{p}<0.001$ vs control. No significant differences were observed between Syn I and Syn $\mathrm{I}+$ ScrPep-E groups $(\mathrm{p}=0.35)$.

Fig. 7. Peptide $\mathrm{E}$ inhibits the synapsin-induced potentiation of $\mathrm{Ca}^{2+}$-triggered vesicle fusion. (A) Representative traces from a fusion experiment. Phospholipid vesicles double labeled with NBD-PE and LRh-PE were mixed with unlabeled vesicles in a 1:4 ratio and the decrease in FRET due to vesicle fusion was followed as a function of time by measuring the increase in the fluorescence emission of the NBD donor (see Experimental). Synapsin I (40 nM) and $\backslash$ or Pep-E (60 $\mu \mathrm{M}$ ) was added $8 \mathrm{~min}$ after the $\mathrm{Ca}^{2+}$ trigger (arrow). (B) For each experimental condition, the fusion extent was calculated by subtracting the fluorescence value recorded immediately before the protein addition from the stable fluorescence value recorded $6 \mathrm{~min}$ after Syn I and/or peptide addition. Data are means \pm s.e.m. of 4 experiments run in triplicate. One way $\operatorname{ANOVA}, F(5,18)=$ 
18.95, $\mathrm{p}<0.001$. Post-hoc Bonferroni's multiple comparison test: ${ }^{*}, \mathrm{p}<0.05,{ }^{* * *} \mathrm{p}<0.001 v \mathrm{~s}$ control; ${ }^{\circ \circ} \mathrm{p}<0.01 ;{ }^{\circ \circ} \mathrm{p}<0.001$ vs Syn I alone.

Fig. 8. Either peptide $\mathbf{E}$ or peptide $\mathrm{C}$ are able to inhibit the synapsin I-induced phospholipid vesicle aggregation. Synapsin I $(200 \mathrm{nM})$, preincubated in the absence or presence of either Pep-E, Pep-C or Pep-C $+200 \mu \mathrm{M}$ Pep-E, was added to a sample of mixed phospholipid vesicles $(20 \mu \mathrm{g}$ of phospholipid/150 $\mu \mathrm{l}$ ). The steady-state turbidity values, recorded by monitoring the optical density at $325 \mathrm{~nm}$ after reaching a stable plateau, are expressed in percent of the respective values measured in the absence of peptides. Points in the plot are the means \pm sem of five independent experiments. Curves were fitted according to a three-parameter logistic function using the program Sigmaplot 10.0 (Systat Software, Inc.). 
Biochemical Journal Immediate Publication. Published on 19 Nov 2009 as manuscript BJ20090762

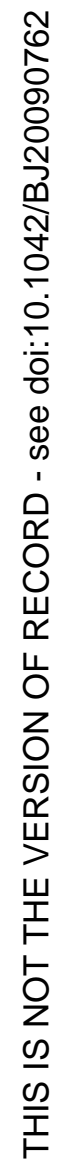
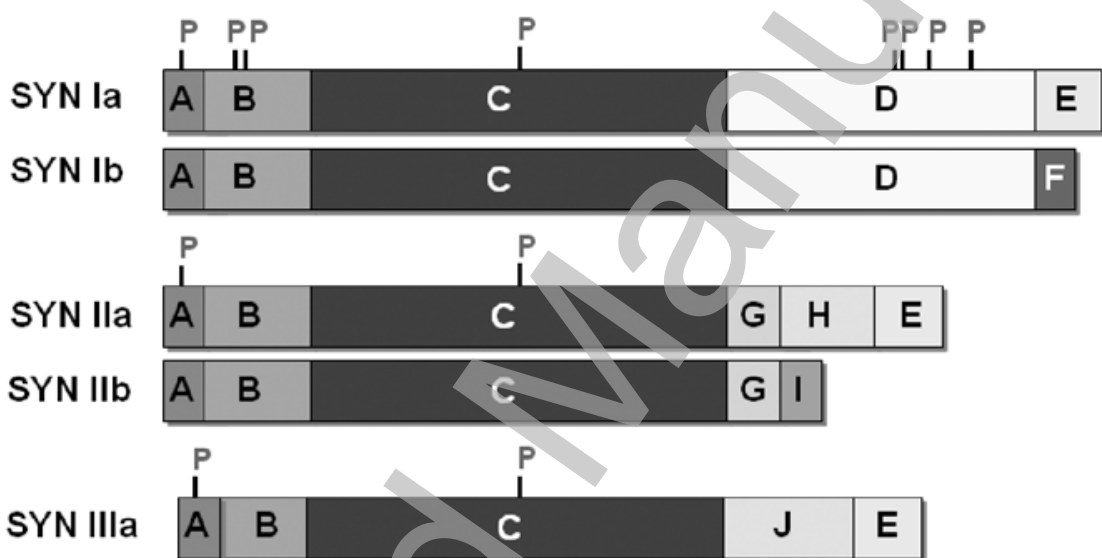

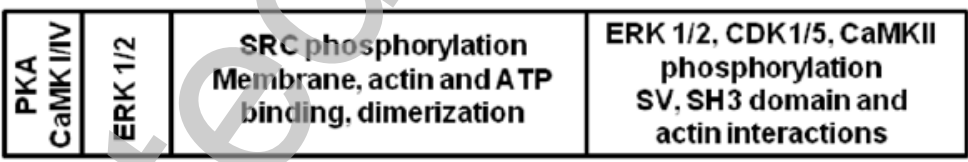

Licenced copy. Copying is not permitted, except with prior permission and as allowed by law. (C) 2009 The Authors Journal compilation (c) 2009 Portland Press Limited 


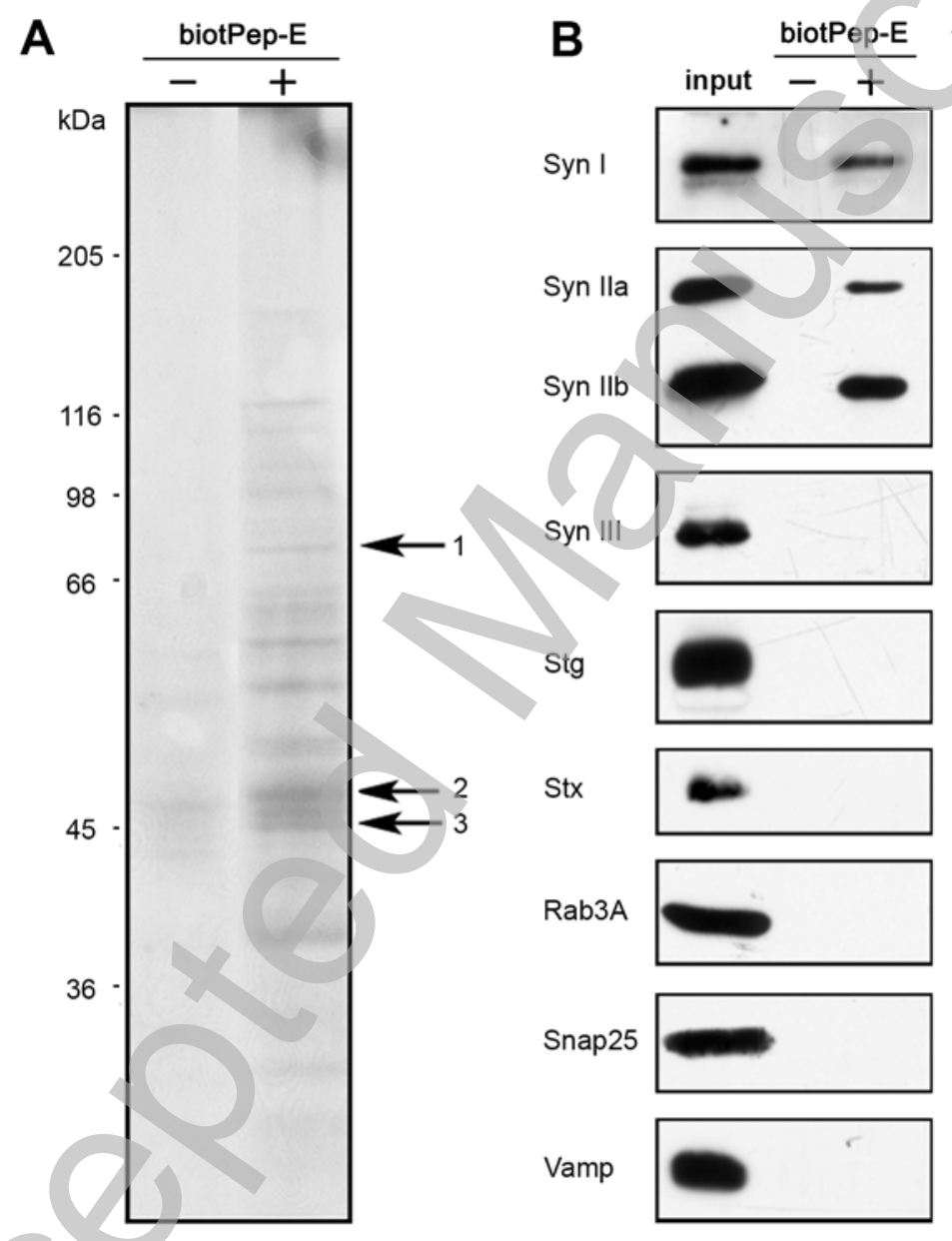


A

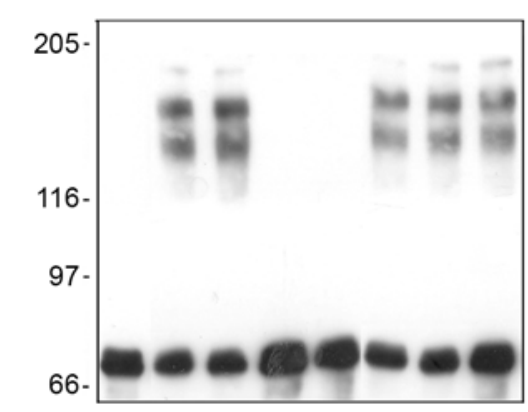

Pep-E - - 125250500 - - -

ScrPep-E - - - - - 125250500

$\mathrm{XL}$ -

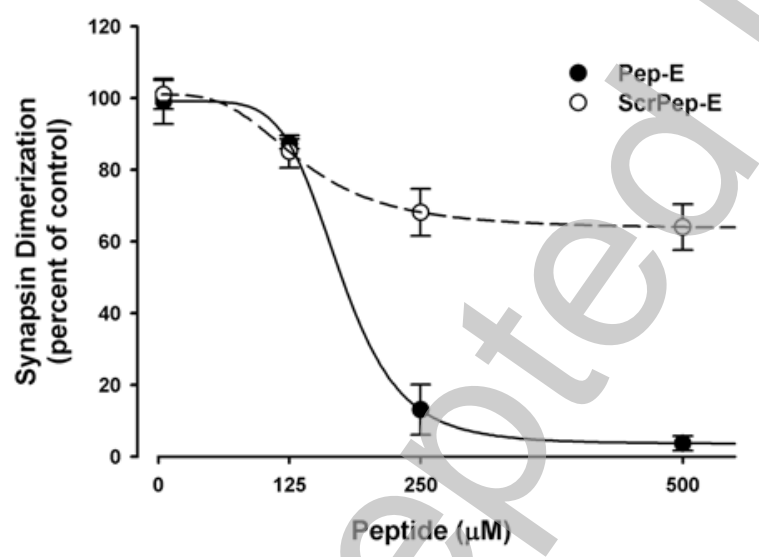

B

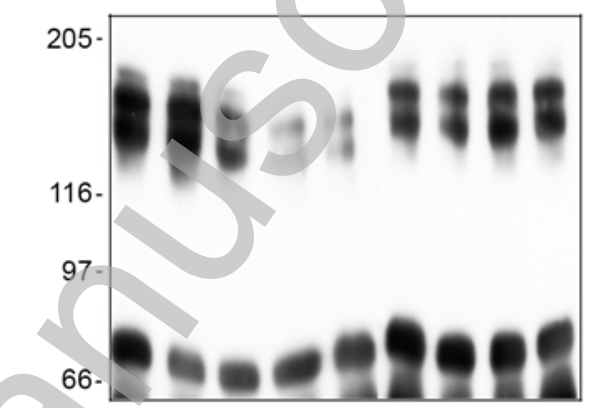

Pep-C - $\begin{array}{llllllllllllllll}10 & 30 & 60 & 120 & - & - & - & -\end{array}$ ScrPep-C - - - - $\quad$ - $1030 \quad 60120$ $\mathrm{XL}$

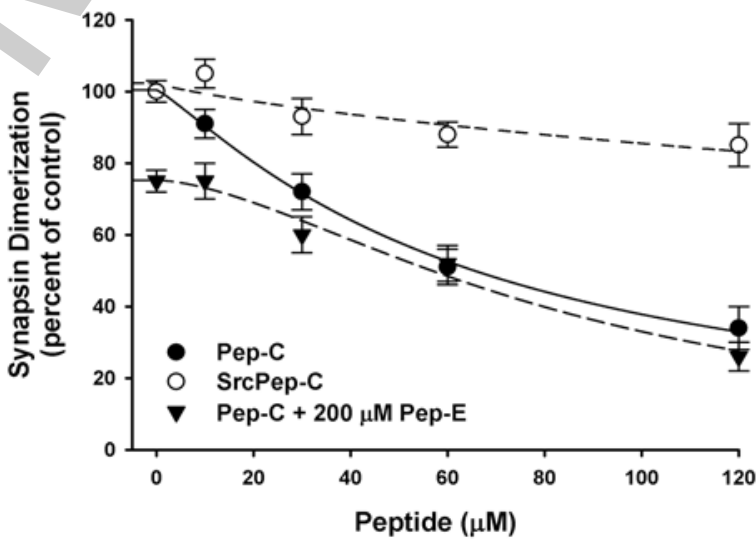



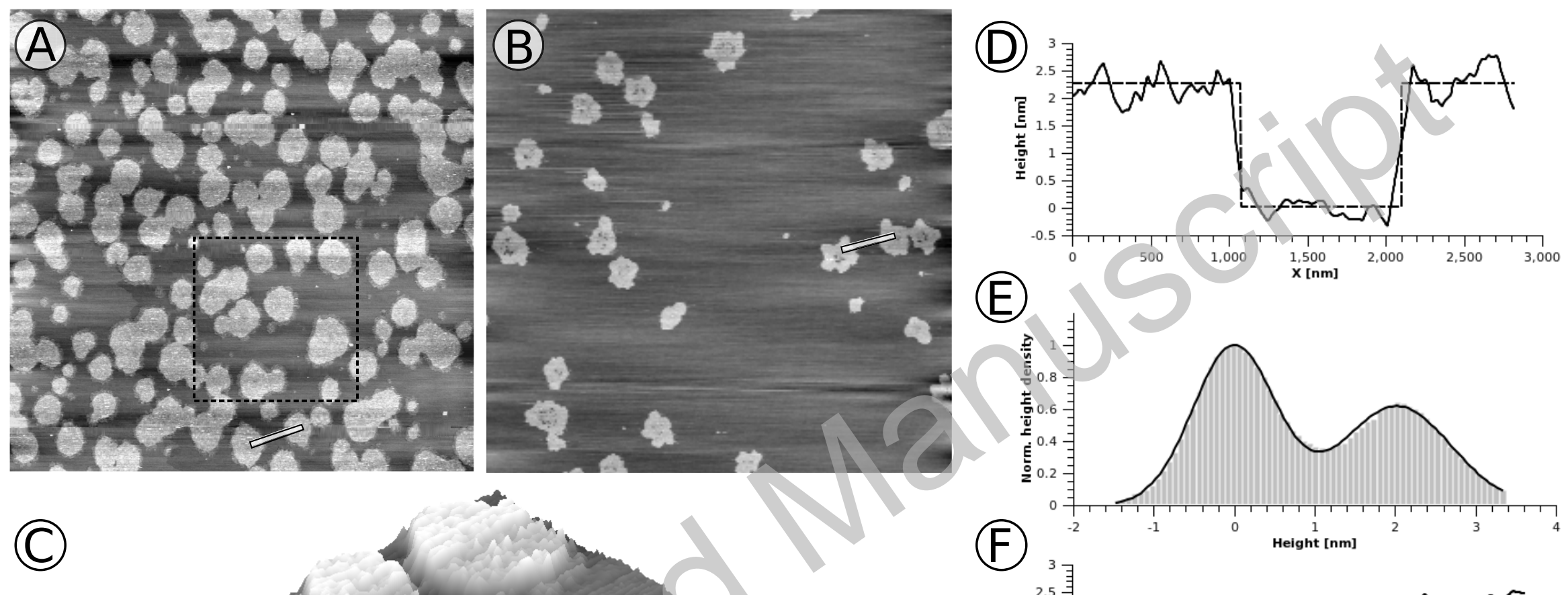

(F)
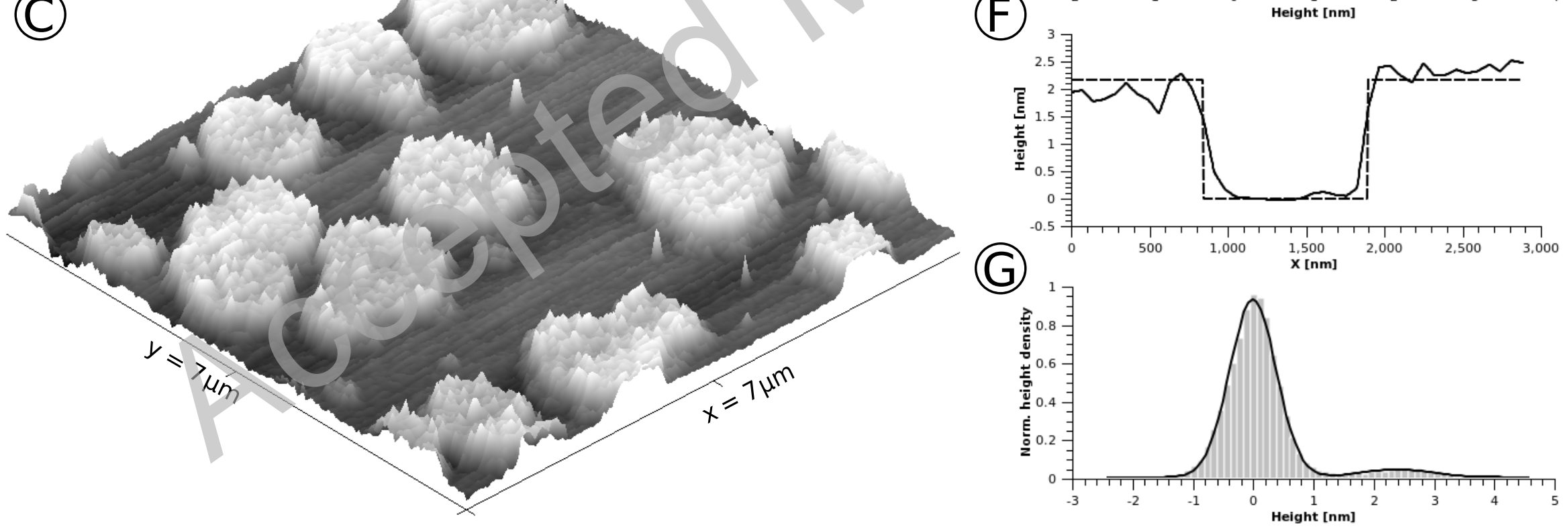

Licenced copy. Copying is not permitted, except with prior permission and as allowed by law. (c) 2009 The Authors Journal compilation (@ 2009 Portland Press Limited 

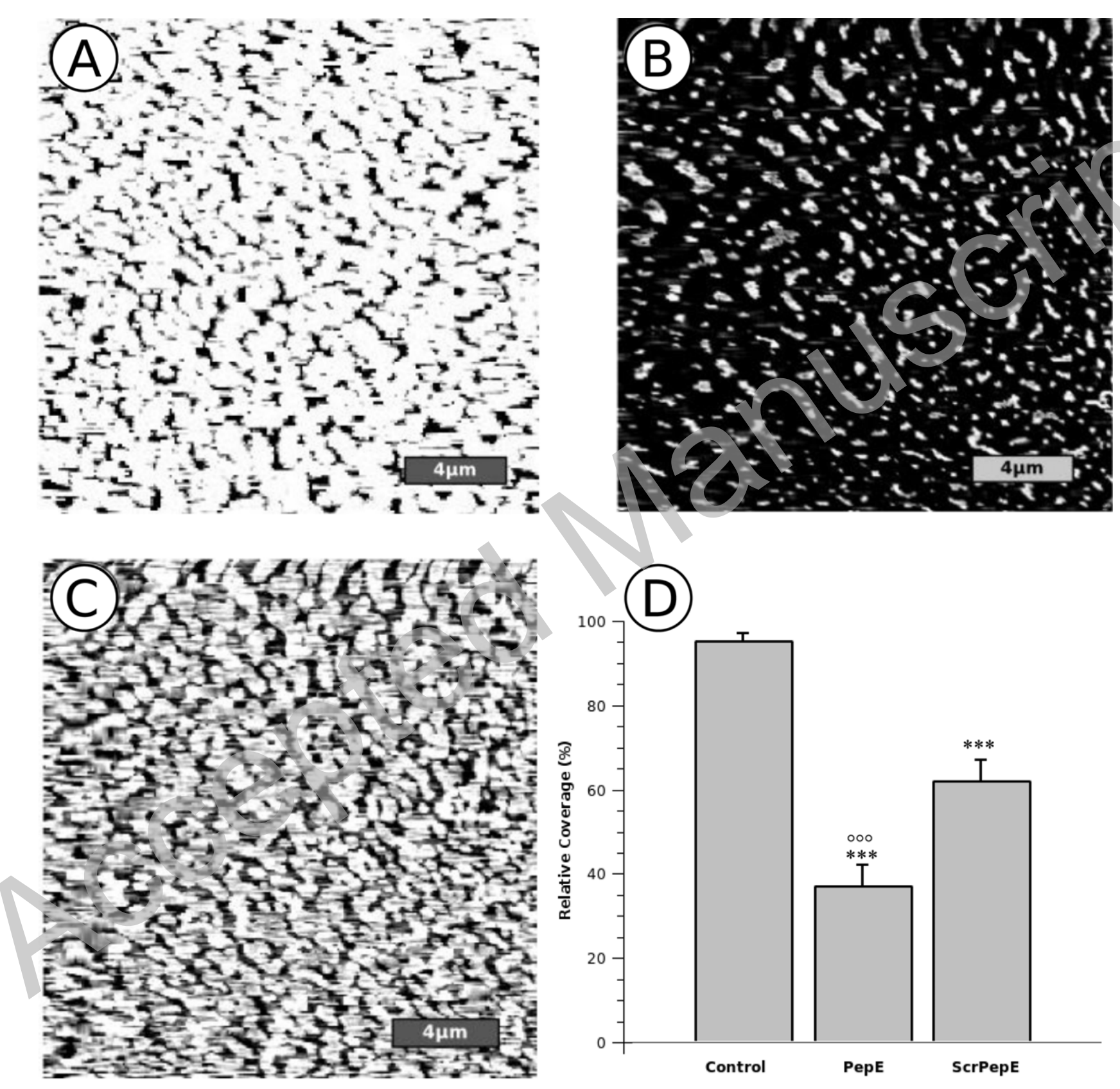

Licenced copy. Copying is not permitted, except with prior permission and as allowed by law. (c) 2009 The Authors Journal compilation ( 2009 Portland Press Limited 

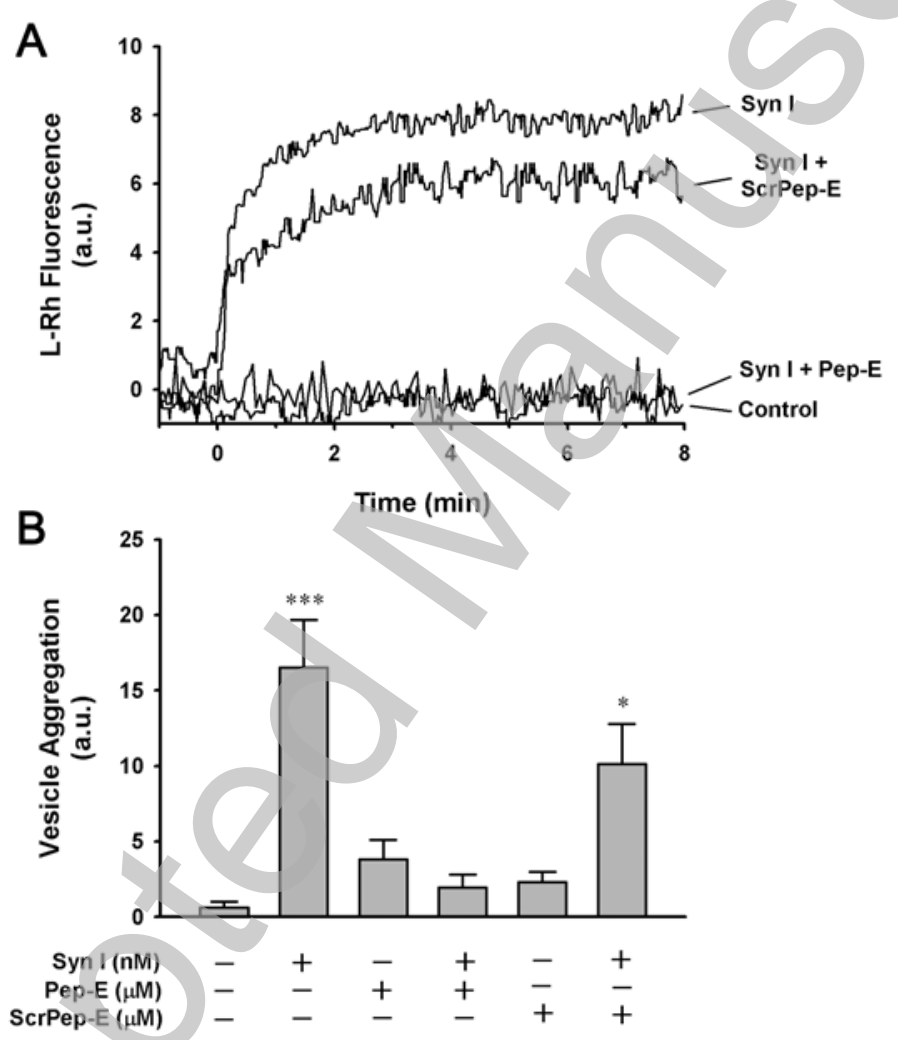

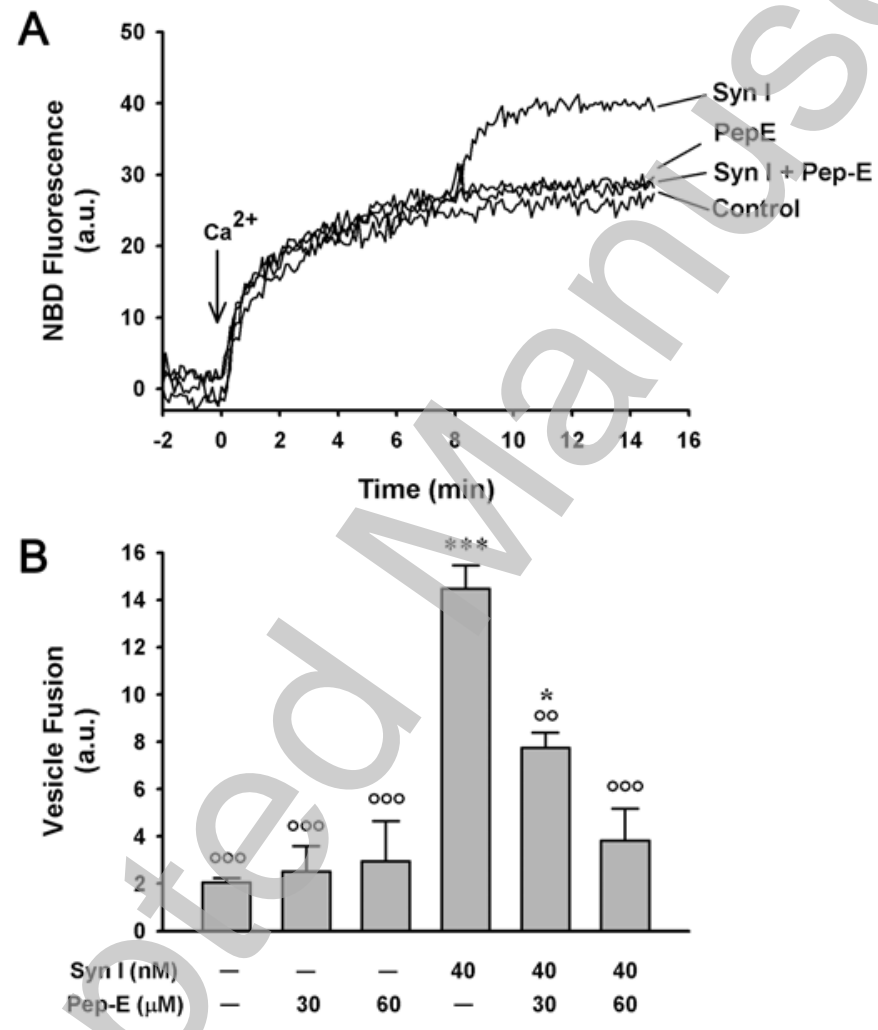


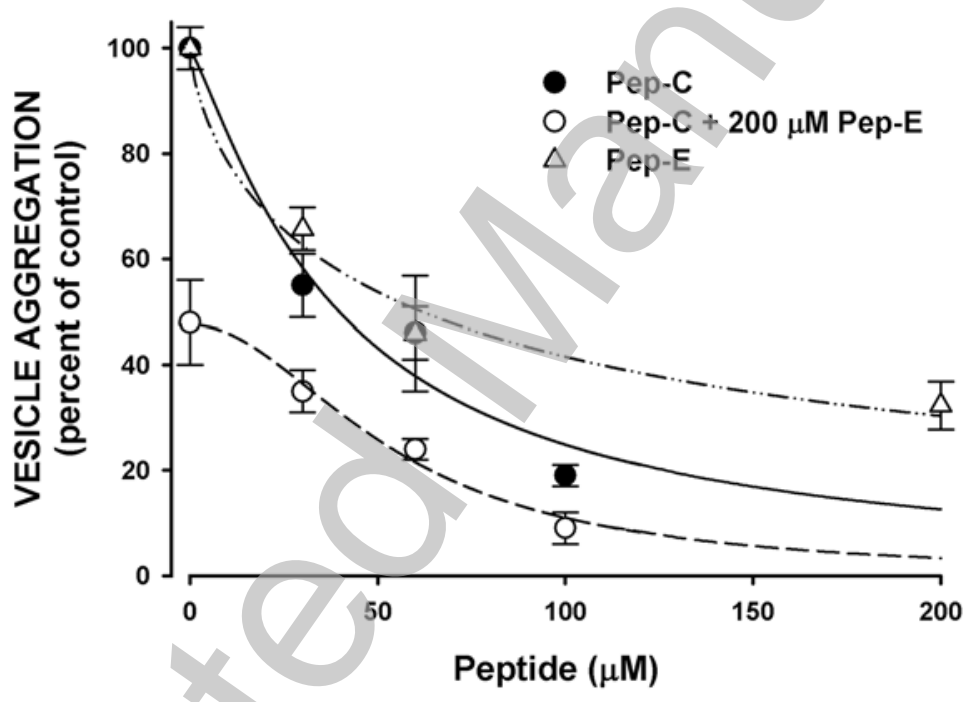

